\title{
PESQUISA QUALITATIVA: A TENSÃO ENTRE A ARTE E O MÉTODO?
}

\author{
FLICK, Uwe. Introdução à pesquisa qualitativa. Tradução Joice \\ Elias Costa - 3 ${ }^{\underline{a}}$ ed. - Porto Alegre: Artmed, 2009. 405 p.
}

Igor Cavallini Johansen*

Fomos brindados recentemente com a terceira edição do livro cuja leitura já se tornou obrigatória entre os estudantes de Ciências Sociais e das ciências humanas de maneira geral: "Introdução à Pesquisa Qualitativa", de Uwe Flick. Apesar do título modesto, que sugere ser esta uma pequena introdução, o livro tem mais de 400 páginas e passa ao largo de uma revisão superficial. O autor é psicólogo e sociólogo, professor titular de pesquisa qualitativa na Alice Salomon University, em Berlim, Alemanha. Flick também é professor auxiliar na Free University of Berlin na área de métodos qualitativos e avaliação e é ainda professor adjunto e chefe do Departamento de Sociologia Médica da Hannover Medical School. Tem como principais interesses de pesquisa os métodos qualitativos, as representações sociais nas áreas da saúde individual e pública e a mudança tecnológica na vida cotidiana.

A abordagem do livro tem em vista dois públicos distintos, apesar de interligados. Um deles compreende os novatos à pesquisa qualitativa e até mesmo à pesquisa social de maneira geral. Para estes, que possivelmente compreendem em sua grande maioria

* Sociólogo pelo Instituto de Filosofia e Ciências Humanas (IFCH-UNICAMP). Aluno de mestrado no Programa de Pós-Graduação em Demografia - IFCHUNICAMP, igorcavallini@gmail.com. 
estudantes de graduação ou pós-graduação, o livro apresenta uma introdução aos princípios e práticas da pesquisa qualitativa. O outro grupo de leitores em potencial abarca os pesquisadores no campo, que podem lançar mão deste livro enquanto aglutinador de ferramentas para fazer frente às questões práticas do cotidiano da pesquisa qualitativa.

O autor deixa claro desde seu capítulo introdutório que a preocupação central do livro é realizar uma apresentação das diferentes etapas no processo da pesquisa qualitativa, o que é feito a partir de uma estruturação lógica das suas partes e capítulos, que visam o desdobramento do processo da pesquisa qualitativa em seus principais estágios. Assim, a estrutura da obra se divide em sete partes.

A Parte I apresenta a estrutura de procedimento da pesquisa qualitativa. O capítulo 1 tem a finalidade de orientar o leitor do começo ao final do livro, descrevendo de forma sumarizada sua organização. $\mathrm{O}$ capítulo 2 contextualiza a história e a fundamentação da pesquisa qualitativa, discutindo tendências, as características e a diversidade das perspectivas de pesquisa. O capítulo 3, por sua vez, coloca em evidência a relação entre pesquisa qualitativa e pesquisa quantitativa apresentando, para além de uma perspectiva reducionista e dicotômica, a importância da complementaridade entre essas duas abordagens de acordo com cada tipo de pesquisa. Já o capítulo 4 enfatiza a importância da ética na pesquisa qualitativa tendo por base a noção de que o pesquisador estará muito próximo de questões da vida particular e cotidiana dos participantes. Põe-se em evidência que ponderação e sensibilidade à problemática da privacidade individual são essenciais antes de se dar início ao trabalho qualitativo. Esta, pois, é uma preocupação que não pode ser deixada em segundo plano na realização de uma pesquisa qualitativa.

Em seguida à delimitação da pesquisa qualitativa, temse a dedicação à compreensão do processo de um estudo qualitativo. A Parte II pretende evidenciar exatamente este ponto. Busca-se aí estabelecer a base epistemológica e teórica para as seções mais teóricas do livro, nas quais o leitor aprenderá 
mais sobre como realizar a pesquisa qualitativa. Nesse sentido, o capítulo 5 discute os modos de utilização das teorias na pesquisa qualitativa, buscando afastar o preconceito segundo o qual é melhor que os pesquisadores se mantenham afastados do contato com a literatura disponível relativa à pesquisa, à metodologia e às teorias sobre objetos de pesquisa.

Em seguida, e em complementaridade com o capítulo 5, o capítulo 6 chama atenção para a importância de se conhecer e descrever sucintamente as principais teorias de embasamento da pesquisa qualitativa, possibilitando reconhecer as características comuns e distintivas destas teorias. O capítulo 7 aborda com maior profundidade dois pressupostos epistemológicos fundamentais: o positivismo e o construtivismo. Nesse ponto, põe-se em evidência o pano de fundo epistemológico do uso de textos, que constitui aspecto comum da pesquisa qualitativa e se impõe nas diferentes posturas teóricas, apresentando também os processos básicos de construção e da compreensão de textos.

A Parte III versa sobre diversos aspectos do processo de pesquisa, tendo como foco o planejamento e elaboração de um plano de investigação. Compreende principalmente os estágios do processo de pesquisa anteriores à coleta e análise dos dados. Assim, ao longo do capítulo 8 comparam-se os diferentes modelos de processo de pesquisa aplicados na pesquisa quantitativa e qualitativa. Pretende-se evidenciar que o processo de pesquisa na pesquisa qualitativa é, usualmente, diferente do processo de etapas claramente definidas da pesquisa quantitativa. Em seguida, abordam-se no capítulo 9 a relevância e os problemas práticos da formação de um bom projeto de pesquisa, explicando a importância da formulação e da focalização nos cuidados da questão de pesquisa.

O capítulo 10 apresenta um título muito propício: "Entrando no campo". Nele discute-se que entrar no campo de pesquisa não compreende apenas um problema técnico para o qual existem soluções simples. Este capítulo pretende deixar claro que nós, enquanto pesquisadores, precisaremos situarmo-nos no campo de discussões já consolidadas sobre nosso objeto de pesquisa. 
O capítulo 11, por sua vez, vem para indicar que, na pesquisa qualitativa, a amostragem é distinta das práticas consagradas na pesquisa quantitativa. Discutem-se aí os modelos e as armadilhas desse tipo de pesquisa. O capítulo 12, para fechar a Parte III, é uma preparação para a etapa seguinte, buscando fornecer algumas dicas de como planejar e construir os planos na pesquisa qualitativa, possibilitando conhecer melhor os componentes básicos que influenciam na construção de um plano de pesquisa.

A Parte IV é o centro da obra-não apenas em sentido concreto, por ser mais ou menos a metade do livro, como também pela sua centralidade de importância no contexto da pesquisa qualitativa. Nesta parte apresenta-se a variedade de métodos utilizados na coleta de dados, com foco principal sobre a palavra falada. Três estratégias básicas são abordadas aqui. A primeira é desenvolvida no capítulo 13, que descreve como usar entrevistas baseadas em perguntas e nas respostas delas extraídas. A estratégia de fazer com que os entrevistados contem suas histórias de vida é desenvolvida no capítulo 14. Já a terceira estratégia é abordada no capítulo 15, que não se refere à realização de entrevistas individuais, mas sim à coleta de dados a partir de grupos. Desenvolvem-se questões acerca de grupos de discussão e a abordagem mais moderna dos grupos focais. O capítulo 16, para encerrar a Parte IV, dedica-se a resumir e comparar as três abordagens para a coleta de dados verbais.

A Parte V, já caminhando para o final, tem foco nos dados multifocais. Essa parte se volta a ampliar o conhecimento do leitor sobre outro tipo de informação, aquele que permite ir além do que dizem os participantes do estudo. Nesse âmbito, a observação, participante e não participante, apresentam longa tradição na pesquisa qualitativa, principalmente no âmbito da etnografia. Assim, o capítulo 17 objetiva esclarecer sobre a variedade de métodos possíveis e de dados coletados desde o processo de observação e de entrevistas até mesmo documentos e demais indícios de interações e de práticas.

O capítulo 18 é diretamente complementar ao anterior, apresentando como filmes, fotografias e vídeos podem se tornar 
formatos ricos de informações para a geração de dados e de questões de pesquisa nos estudos qualitativos. Em seguida, o capítulo 19 apresenta estratégias de utilização de documentos enquanto fontes de informação para a pesquisa, ao passo que estes podem ser analisados como traços de experiências pessoais ou de interações institucionais. O capítulo 20 indica as promessas e ciladas das novas tecnologias de informação, como o e-mail, a internet, os chats e grupos de notícia ou de discussão. Vários avanços advêm daí, mas também é preciso atentar aos limites e possíveis armadilhas que essas estratégias de análise trazem à pesquisa qualitativa. $\mathrm{O}$ capítulo 21 , enfim, resume e compara as diversas abordagens tangentes à coleta de dados multifocais.

A Parte VI propõe um outro estágio da pesquisa, o de, com os dados em mãos, voltar-nos para sua análise, o que implica diversas etapas. A princípio, é necessário que o pesquisador documente aquilo que observou ou o que lhe foi dito para ter uma boa base de análise. O capítulo 22 trata da documentação, apresentando o uso das notas de campo na observação e transcrição após o processo de entrevista. Em seguida, o capítulo 23 coloca em evidência varias técnicas de codificação e de categorização de dados. O capítulo 24, em complementaridade com o anterior, volta-se aos procedimentos de análise de conversação e do discurso, pretendendo colocar em evidência como as questões são construídas a partir da forma como as pessoas discutem ou como os discursos são produzidos, assim como as representações dos meios de comunicação.

O capítulo 25, por sua vez, aborda os procedimentos hermenêuticos e a análise de narrativa da questão e seu significado. Já o capítulo 26 versa sobre o potencial e limitações dos programas de computador para análise de dados qualitativos. Enfim, o capítulo 27 trata de apresentar uma visão geral das diversas abordagens e técnicas analíticas dos dados coletados em campo durante a pesquisa qualitativa.

A última seção do livro, a Parte VII, aborda o embasamento e a redação da pesquisa qualitativa. O capítulo 28 apresenta uma visão geral dos vários critérios de como avaliar a pesquisa qualitativa e das discussões a eles associadas. Já o capítulo 29 aponta para 
as estratégias voltadas para o processo de controle de qualidade na pesquisa possibilitando, inclusive, distinguir os problemas e as formas de generalização na pesquisa qualitativa. O capítulo 30 , por seu turno, trata do tema de como apresentar a pesquisa, ou o problema da redação, que se torna também uma questão de legitimidade. Argumenta-se que os problemas associados a essa questão podem levar a pesquisa qualitativa de volta à tensão entre uma arte sofisticada e um método epistemologicamente acurado.

Nesta obra, como se pode perceber, conta-se com uma análise geral do processo de construção da pesquisa qualitativa, desde suas bases teórico-metodológicas até a análise dos dados provenientes desse procedimento metodológico e as formas de redação dos dados, de modo a assegurar sua legitimidade. $\mathrm{O}$ autor coloca em evidência que a pesquisa qualitativa construída de forma rigorosa, bem direcionada e consciente dos seus pressupostos teóricos, assim como de seus alcances e limites é e continuará sendo uma ferramenta essencial para a ampliação do conhecimento nas ciências sociais e nas ciências humanas de maneira mais ampla.

Ao longo dessa leitura, leve e ao mesmo tempo rica em detalhes, garantida pelo rigor e didatismo de Uwe Flick, vê-se a importância de trazer à baila esta metodologia que é tão cara aos estudos das sociedades humanas, reconhecendo seu poder de alcance e sua legitimidade a partir da vigilância epistemológica e da construção teórica, que são marcas historicamente constituídas na nossa forma específica de construir conhecimento.

Este livro surge no contexto da necessidade de romper com a falsa problemática que envolve a pesquisa qualitativa, colocada em uma corda-bamba entre a arte e o método. Também fazemos arte. Trata-se da arte da inventividade, da criação, da inovação, da engenhosidade. Mas diante de toda a exposição da complexidade inerente à aplicação da pesquisa qualitativa; dos desafios de garantir o rigor dos procedimentos e a confiabilidade dos seus resultados; assim como da importância de vigiar para que se expresse esse conhecimento da maneira mais clarividente possível, respeitando o limite das técnicas que utilizamos, podemos dizer, sem medo de ser felizes, que fazemos arte. Arte com método! 